\title{
Probabilistic Analysis of the Spatio-Temporal Soil Saturation and Water Level Variability of the Pugllohuma Peatland Using Synthetic Aperture Radar Images of the Sentinel-1 Mission ${ }^{\dagger}$
}

\author{
Paul David Carchipulla-Morales ${ }^{1,2, *(D)}$ and Xavier Zapata-Ríos ${ }^{1,2}$ \\ 1 Department of Civil and Environmental Engineering, Escuela Politécnica Nacional, Quito 170517, Ecuador; \\ xavier.zapata@epn.edu.ec \\ 2 Center for Research and Water Resources Studies, Escuela Politécnica Nacional, Quito 170517, Ecuador \\ * Correspondence: paul.carchipulla@epn.edu.ec \\ + Presented at the 8th International Symposium on Sensor Science, 17-28 May 2021; Available online: \\ https://i3s2021dresden.sciforum.net/.
}

check for updates

Citation: Carchipulla-Morales, P.D.; Zapata-Ríos, X. Probabilistic Analysis of the Spatio-Temporal Soil

Saturation and Water Level Variability of the Pugllohuma Peatland Using Synthetic Aperture Radar Images of the Sentinel-1 Mission. Eng. Proc. 2021, 6, 64. https: / / doi.org/10.3390/ I3S2021Dresden-10120

Academic Editors: Gianaurelio Cuniberti and Larysa Baraban

Published: 17 May 2021

Publisher's Note: MDPI stays neutral with regard to jurisdictional claims in published maps and institutional affiliations.

Copyright: (c) 2021 by the authors. Licensee MDPI, Basel, Switzerland. This article is an open access article distributed under the terms and conditions of the Creative Commons Attribution (CC BY) license (https:/ / creativecommons.org/licenses/by/ $4.0 /)$.

\begin{abstract}
This study presents the spatio-temporal assessment of the Pugllohuma peatland's soil saturation and water level variability. The Pugllohuma is a high elevation wetland located within the Sustainable Water Conservation Area Antisana in the northern Andes of Ecuador above 4100 m.a.s.l. This assessment provides information of the dry and wet seasons in the Pugllohuma peatland. The temporal variability was investigated considering variables such as: atmospheric pressure, rainfall, relative humidity, air temperature, wind speed and direction records of two near meteorological stations, while the spatial variability was investigated through images of the Sentinel-1 mission from 2017 to 2019, and terrain characteristics such as: elevation and slope. Image analysis and degree of soil saturation classification were carried out using the R programming language and Google Earth Engine, and the results were published in the UI service in Google Apps Script.
\end{abstract}

Keywords: Sentinel-1; wetland; Google Earth Engine; random forest

\section{Introduction}

The study of environmentally sensitive areas and their ecosystem services is relevant worldwide because of their importance to anthropic interests and activities. The Pugllohuma peatland is located within the water conservation area Antisana which is the source of water to La Mica Quito Sur water supply system, which is one of the four water collection systems used in Quito the capital of Ecuador. Therefore, its conservation is fundamental for hydrological processes and the water that reaches Quito's drinking water network [1]. Commonly, the use of optical images to study wetlands has the disadvantage to include data gaps as a consequence of cloud cover and volcanic plumes [2,3]. Therefore, this research used radar images to detect changes in the peatland's soil saturation and water levels from 2017 to 2019 . The radar image classification process was developed by decision trees to perform supervised classifications of soil saturation and water levels [4,5]. Thereby, the building of the degree of soil saturation supervised classification models showed that Pugllohuma peatland's space-time changes are governed by the day of the year, terrain elevation, air temperature, and rainfall. The wetland surface extension is small when soils are dry during the dry season which takes place during January, February, and March. Whereas high water tables were frequent from June to September and from November to December. The study area showed seasonal changes above and below the following degree of soil saturation surface areas: 170 ha of dry soil, 17 ha of moist soil, and 7 ha of soil near saturation. 


\section{Materials and Methods}

We took advantage of the local meteorological datasets and the Sentinel-1 imagery for assessing the changes in the soil saturation and water levels of the Pugllohuma peatland. Figure 1 shows a flowchart highlighting the datasets used and key methodological steps. This workflow involved three primary steps:

1. Generation of temporal supervised classification using R Studio.

2. Imagery selection and pre-processing using Google Earth Engine.

3. Generation of spatial supervised classification using Google Earth Engine.



Figure 1. Workflow of Pugllohuma peatland's soil saturation degree supervised classification: (a) Temporal classification. (b) Spatial classification. The parallelograms were used for data, rectangles for activities, diamonds for decisions, and rounded rectangles for products.

Additionally, we included the use of correlation matrices, plots of Out of Bag (OOB) errors against number of trees, as well as the Mean Decrease Accuracy and Mean Decrease Gini index to build and assess the classification models.

The temporal degree of saturation supervised classification was used to classify the extreme dry and wet events in the peatland, based on water table and meteorological data [6-8]. Later, the dates of climate extreme events were used in the imagery selection, in which pixel values were identified to different land cover classes such as: water, flooded vegetation, and dry soils (e.g., roads surfaces). Finally, the backscattering, terrain data, and the day of the year of the imagery were used to classify the soil saturation and water levels variability in the Pugllohuma' s peatland from 2017 to 2019 [9]. 


\section{Results}

\subsection{Extreme Climate Events}

While collecting meteorological data for the classification, it was observed that wet extreme events occurred frequently from April to June and from October to December. In contrast, the dry extreme events were frequently observed in January, February, July, August, and September. The main variables for identifying extreme climate events were the day of the year, air temperature, rainfall, and terrain elevation. In Figure 2, it is shown the temporal distribution of dry and wet extreme events, and the probability of a date to be one of those two classes.

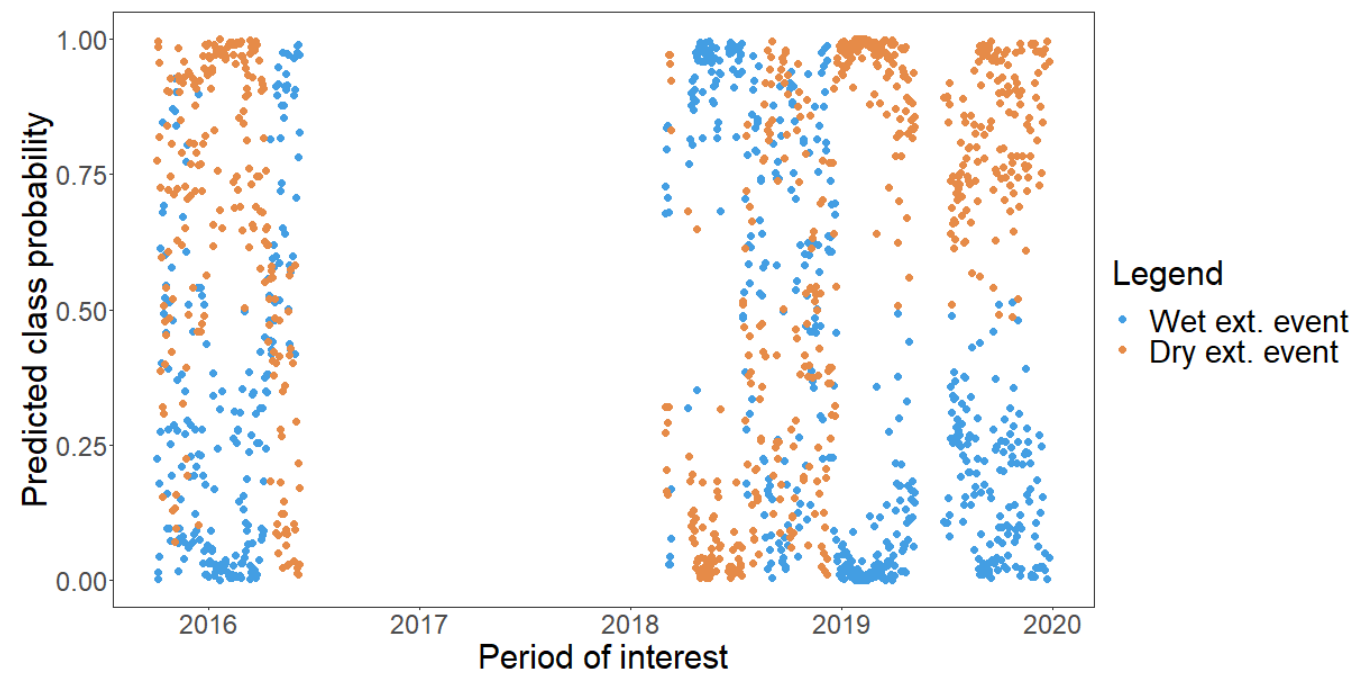

Figure 2. Temporal distribution of the dry and wet extreme events.

\subsection{Spatio-Temporal Classification of SAR Images Time Series}

The temporal variation of dry, wet and saturated soils may be observed in Figures 3-5, where in grey color bars are shown extreme events. From our analysis it is clear that soil saturation within the peatland was related to extreme climate events. In general, the peatland was (i) dry from January to March, and (ii) it was wet from June to September and from November to December. Moreover, SAR imagery showed more soil saturation and water level variability in the center and southern parts of the wetland, and occasional soil saturation towards the southwestern of the wetland. Areas of abundant vegetation showed permanent accumulation of water.

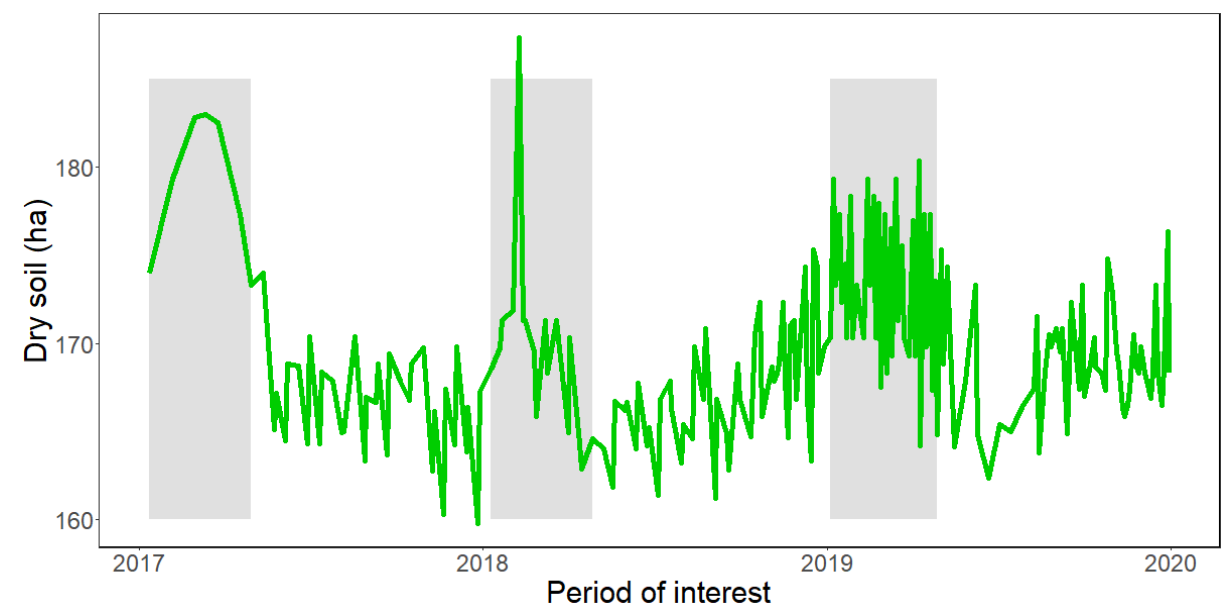

Figure 3. Evolution of the spatio-temporal classification of dry soil. 




Figure 4. Evolution of the spatio-temporal classification of wet soil.

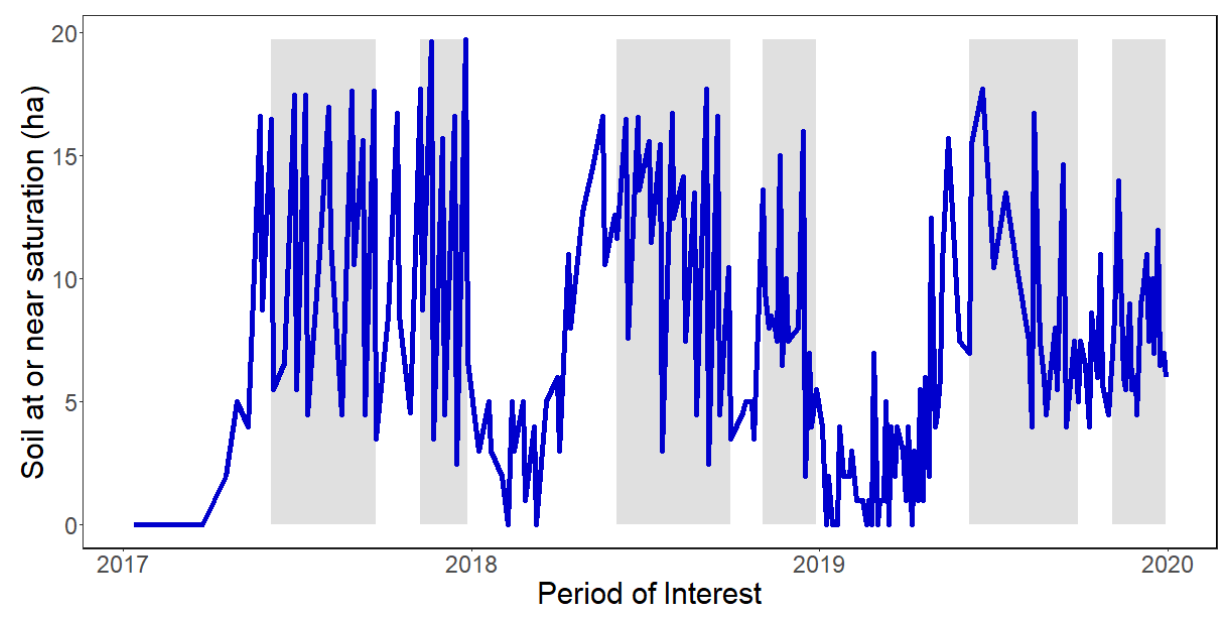

Figure 5. Evolution of the spatio-temporal classification of soil at or near saturation.

\subsection{Results Validation}

The soil saturation degree supervised classification by using SAR images was compared with soil saturation degree unsupervised classification based on optical images. The comparison between supervised and unsupervised classifications indicated that using radar images was more accurate when evaluating the spatial distribution of classes on surfaces larger than 20 ha due to the correction required for radar images by the speckle effect. Moreover, the results of both classifications were similar across $70 \%$ of the surface. The mean soil saturation degree had a spatial distribution of dry, wet and saturated soils of $170 \mathrm{ha}, 17 \mathrm{ha}$, and $7 \mathrm{ha}$, respectively. However, the maps of the supervised classification showed sharper boundaries between classes than those presented in the unsupervised classification. The difference between both results denoted the sensitivity of optical sensors to changes in vegetation and the sensitivity of radar sensors to topographic changes due to the water content in the Andean vegetation and surface morphology.

Supplementary Materials: The video of the presentation at the 8th International Symposium on Sensor Science is available at https: / www.mdpi.com/article/10.3390/I3S2021Dresden-10120/s1.

Author Contributions: Conceptualization, PCM and XZR; methodology PCM software, PCM; validation, PCM; formal analysis, PCM; investigation PCM; resources, XZR; data curation, PCM; writingoriginal draft preparation, PCM; writing - review and editing, XZR; visualization, PCM; supervision, XZR project administration, XZR; funding acquisition, XZR. All authors have read and agreed to the published version of the manuscript. 
Funding: This research was funded by Escuela Politécnica Nacional under the framework of project PIJ-17-05: global climatic patterns and their influence on the temporal and spatial response of spectral indices of the paramo vegetation in Ecuador.

Institutional Review Board Statement: Not applicable.

Informed Consent Statement: Not applicable.

Data Availability Statement: The supervised classification results are available at https://pij-17-0 5.users.earthengine.app/view/sar-landtrendr, and the comparison between both classifications is available at https:/ / pij-17-05.users.earthengine.app/view/landtrendrassessment. Both data repositories were last accessed on 18 August 2021.

Conflicts of Interest: The authors declare no conflict of interest.

\section{References}

1. FONAG. Informe De Cumplimiento De Metas_Plan De Monitoreo 2019; Technical Report; Fondo para la Protección del Agua: Quito, Ecuador, 2019.

2. Schroeder, R.; Rawlins, M.A.; McDonald, K.C.; Podest, E.; Zimmermann, R.; Kueppers, M. Satellite microwave remote sensing of North Eurasian inundation dynamics: Development of coarse-resolution products and comparison with high-resolution synthetic aperture radar data. Environ. Res. Lett. 2010, 5. [CrossRef]

3. Guo, M.; Li, J.; Sheng, C.; Xu, J.; Wu, L. A review of wetland remote sensing. Sensors 2017, 17, 777. [CrossRef]

4. Huang, W.; DeVries, B.; Huang, C.; Lang, M.W.; Jones, J.W.; Creed, I.F.; Carroll, M.L. Automated extraction of surface water extent from Sentinel-1 data. Remote Sens. 2018, 10, 797. [CrossRef]

5. Mahdianpari, M.; Salehi, B.; Mohammadimanesh, F.; Homayouni, S.; Gill, E. The first wetland inventory map of newfoundland at a spatial resolution of $10 \mathrm{~m}$ using sentinel-1 and sentinel-2 data on the Google Earth Engine cloud computing platform. Remote Sens. 2019, 11, 43. [CrossRef]

6. Taylor, C.J.; Alley, W.M. Ground-Water-Level Monitoring and the Importance of Long-Term Water-Level Data; U.S. Geological Survey: Denver, CO, USA, 2001; pp. 1-68.

7. Shepherd, T. Measuring Water Levels in Wells; Technical Report; Department of Health, Department of Ecology: Tacoma, WA, USA, 2009.

8. Schumacher, J.G.; Klesschulte, M.J. Investigation of a Monitoring Well Completed in the St. Francois Aquifer in Oregon County, Missouri, 2005-08 Scientific Investigations Report 2010-5041; U.S. Geological Survey Scientific Investigations: St. Louis, MO, USA, $2010 ;$ p. 22. [CrossRef]

9. Jensen, K.; McDonald, K.; Podest, E.; Rodriguez-Alvarez, N.; Horna, V.; Steiner, N. Assessing L-Band GNSS-reflectometry and imaging radar for detecting sub-canopy inundation dynamics in a tropicalwetlands complex. Remote Sens. 2018, $10,1431$. [CrossRef] 